Department of Anatomy and Human Biology, The

University of Western Australia, Nedlands Perth, 6907, Western Australia

J Djano

I van Bruggen

P G McMenamin

Centre for Microscopy and Microanalysis B Griffin

Correspondence to: P G McMenamin

Accepted for publication 18 August 1999

\title{
Environmental scanning electron microscopic study of macrophages associated with the tunica vasculosa lentis in the developing rat eye
}

\author{
J Djano, B Griffin, I van Bruggen, P G McMenamin
}

\begin{abstract}
Aims-To demonstrate the value of environmental scanning electron microscopy (ESEM) when used in combination with immunogold/silver enhancement methods as a valuable tool in ocular research, and to determine the phenotype of macrophages associated with the tunica vasculosa lentis while maintaining a topographical view of the lens surface.

Methods-Prenatal and postnatal rat eyes were investigated by conventional scanning electron microscopy and ESEM. In the latter case tissues were prestained with a panel of antileucocyte monoclonal antibodies and visualised with colloidal gold conjugated secondary antibody followed by silver enhancement.

Results-The preliminary data demonstrate that $\mathrm{ED1}^{+} \mathrm{ED2}^{+}$macrophages occur in large numbers around the lens and are associated with sectors of both normal vessels and those undergoing regression.

Conclusion-The present study demonstrates that ESEM is an ideal way to combine scanning electron microscopy with immunohistochemistry and is therefore likely to have multiple other applications in ocular research.

(Br f Ophthalmol 1999;83:1384-1385)
\end{abstract}

Disruption of the normal mechanisms which control growth and regression of the temporary vascular networks associated with the developing lens and retina can lead to a number of congenital ocular abnormalities such as persistent pupillary membrane, persistent hyperplastic primary vitreous, congenital cataract, and retinopathy of prematurity. Several elegant scanning electron microscopic (SEM) studies have been performed in a number of species. These display the gradual regression of the tunica vasculosa lentis (TVL), part of the network of vessels covering the surface of the developing lens. ${ }^{1-3}$ In humans these vessels regress in the last trimester, but in some laboratory animals the regression occurs post partum thus making them accessible for experimental studies. Recent investigations in mice have suggested that macrophages (often termed "hyalocytes") play an active part in the induction of apoptosis in vessels of the TVL during this regression ${ }^{4}$ although others suggest a more passive role ${ }^{5}$. Immunophenotypic identification of macrophage subpopulations has been performed to only a limited extent on mouse whole lenses or TVL whole mounts at the light microscopic level. ${ }^{45}$

Environmental scanning electron microscopy (ESEM) is a relatively new technique that makes it possible to examine practically any material, including biological tissues, wet or dry, insulating or conducting, because it allows the introduction of a gaseous environment in the specimen chamber. A gaseous detection device enables images to be obtained in secondary (SE) mode. This signal is mixed with the backscattered (BSE) electron image to provide strong material and morphological contrast. ${ }^{67}$ As there is no need for conductive coating of biological material immunophenotypic characterisation of cells can be achieved by staining with colloidal gold reagents (conjugated antibodies or streptavidin-gold) with subsequent silver enhancement. ${ }^{8}$ Labelled cells can then be readily detected by ESEM in the context of the surrounding surface tissue architecture. To our knowledge this technique has not been applied previously to ocular tissues. The aim of this brief report is to demonstrate the value of this novel ESEM approach in immunophenotypic analysis of macrophages and the TVL during rat lens development.

\section{Materials and methods}

Wistar rats (P20, day $0,2,5,10$ post partum) were sacrificed and the eyes enucleated and fixed in either a mixture of glutaraldehyde $(2.5 \%)$ and paraformaldehyde $(2 \%)$ in phosphate buffer (for conventional SEM) or paraformaldehyde alone (4\%) (for ESEM). Following removal of the posterior segment the lens and enveloping TVL within the anterior segment were processed in the conventional fashion for SEM (dehydration, critical point drying, and sputter coated with gold). Samples were examined in a Philips 505 SEM at 15-30 $\mathrm{kV}$ in SE mode. Tissue for ESEM was incubated in primary monoclonal antibodies 


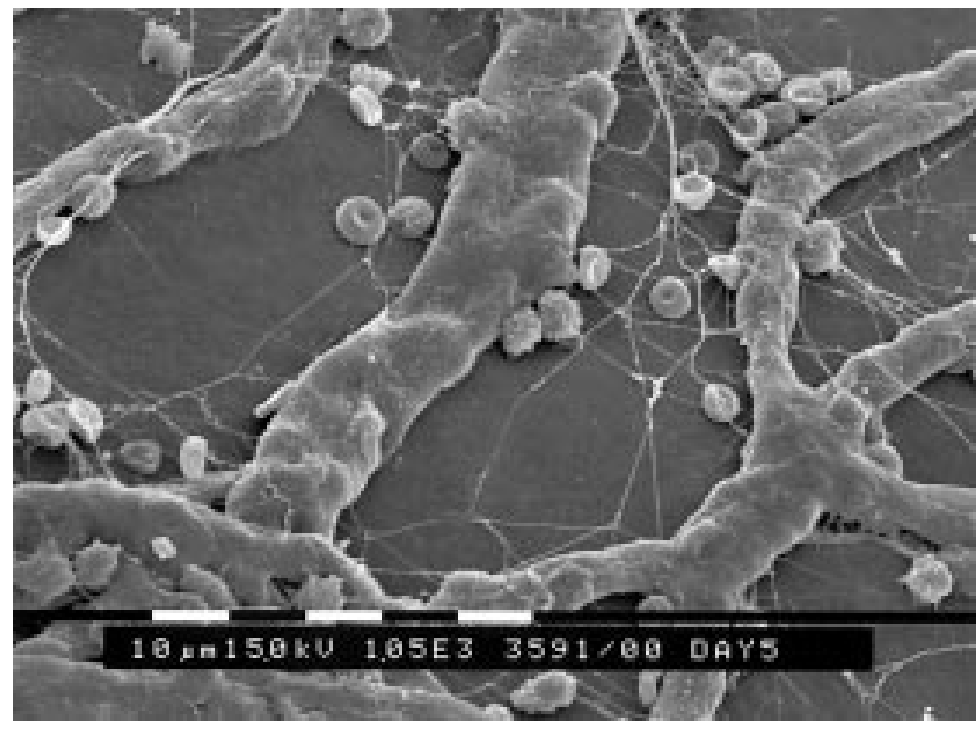

Figure 1 Conventional scanning electron microscopic view of the tunica vasculosa lentis in the developing rat eye (5 days postnatal) showing the numerous macrophage-like cells on the lens surface and around the vessels. Vitreal collagen and some erythrocytes, which most probably leak from vessels during dissection of the eye or from vessels undergoing regression, are also visible on the lens surface.
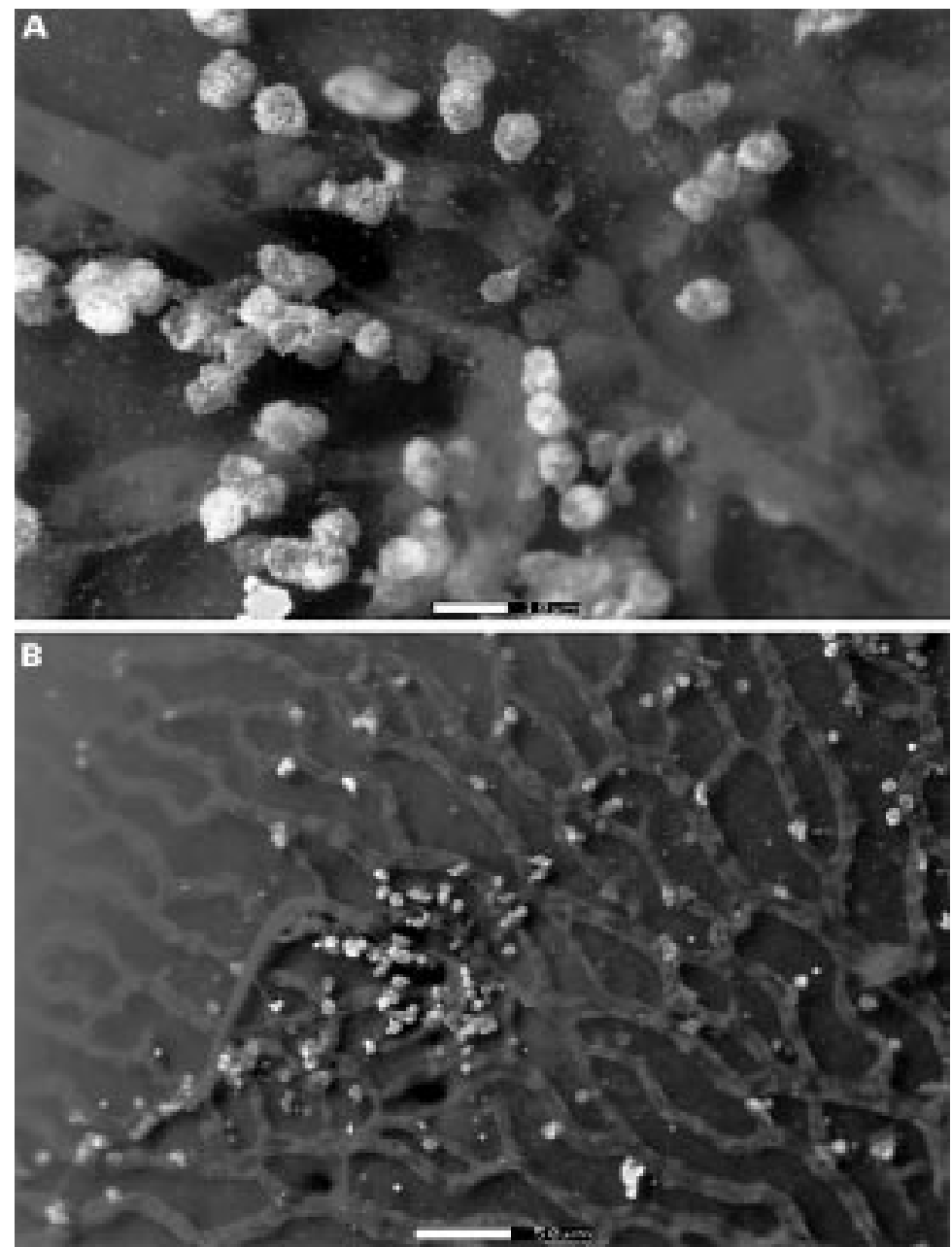

Figure 2 Environmental scanning electron microscopic view ( $A$, high power; $B$, low power) of the tunica vasculosa lentis in the developing rat eye (day 2) which has been stained with the anti-macrophage monoclonal antibody ED2. Immunopositive (silver enhanced) macrophages are the brightly labelled cells.
(mAbs), goat anti-mouse IgG-1 nm gold conjugate (British Biocell International) followed by silver enhancement. ${ }^{7}$ Tissues were then critical point dried and mounted on carbon tape. No coating of specimens is required for ESEM. Specimens were examined with an Electroscan E3 ESEM using BSE mode $(5-30 \mathrm{kV})$.

\section{Results and discussion}

Conventional SEM revealed numerous macrophage-like cells, or "hyalocytes", associated with the TVL in the developing rat eye at all age groups (Fig 1). These were similar in morphology and distribution to those described in previous studies. ${ }^{13}$ The use of ESEM allowed us for the first time to reveal that these cells were immunoreactive for the mAbs ED2 (pan-specific marker of all resident tissue macrophages in rat) (Fig 2) and ED1 (CD68) (not shown). They were CD11b (Ox42 mAb, reacts with retinal microglia) and major histocompatibility class $\mathrm{II}^{-}(\mathrm{Ox} 6 \mathrm{mAb})$. This phenotype is consistent with resident connective tissue macrophages in the rat.

The ESEM technique offers the examiner a unique perspective of the surface architecture similar to conventional SEM (Fig 1) yet also allows the combined use of immunohistochemical staining (Fig 2). In addition, by using increased accelerating voltages (such as $30 \mathrm{kV}$ ) one can obtain information from beneath the surface of the tissue-for example, red blood cells can be seen within the lumen of vessels. The success of this pilot study will allow us to determine whether numbers, spatial distribution, and phenotype of macrophages has temporal and/or spatial associations with the regressing TVL. This technique could prove invaluable in the investigation of other ocular cells and tissues which are amenable to conventional SEM investigations such as the corneal-conjunctival surface, corneal endothelium, trabecular meshwork, iris, inner retinal surface, and many other sites both in normal and diseased states.

1 Latker C, Kuwabara T. Regression of the tunica vasculosa lentis in the postnatal rat. Invest Ophthalmol Vis Sci 1981;21:689-99.

2 Sellheyer K, Spitznas M. Ultrastructure of the human posterior tunica vasculosa lentis during early gestation. Graefes terior tunica vasculosa lentis during early ges

3 El-Hifnawi E, El-Hifnawi A, Frankenberg $\mathrm{Ch}$, et al. Ultrastructure and regression of the tunica vasculosa lentis in newborn Wistar rats. Ann Anat 1994;176:143-9.

4 Lang R, Bishop J. Macrophages are required for cell death and tissue remodelling in the developing mouse eye. Cell 1993;74:453-62.

5 Mitchell C, Risau W, Drexler H. Regression of vessels in the tunica vasculosa lentis is initiated by coordinated endothelial apoptosis: a role for vascular endothelial growth factor as a survival factor for endothelium. Dev Dynamics 1998;213:322-33.

6 Danilatos CD. Introduction to the ESEM instrument. Microsc Res Tech 1993;25:354-61.

7 Griffin BJ, van Riessen A, Egerton-Warburton L. A review of qualitative and quantitative EDS x-ray microanalysis of hydrated and non-hydrated samples, and associated imaging strategies. In: Etz, E, ed. Proc Microbeam Analysis. ing strategies. In: Etz, E, ed. Proc Microbeam Anal
Breckenridge. New York: VCH Publishers, 1995:383.

8 Herter P, Laube G, Gronczewski J, et al. Silver enhanced colloidal-gold labelling of rabbit kidney collecting-duct cell surfaces imaged by scanning electron microscopy. F Microsc 1993;171:107-15. 